\title{
Journal of Thermal Analysis and Calorimetry \\ Kinetic analysis of the thermal decomposition of liquid ammonium nitrate based on thermal analysis and detailed reaction simulations \\ --Manuscript Draft--
}

\begin{tabular}{|c|c|c|}
\hline Manuscript Number: & \multicolumn{2}{|l|}{ JTAC-D-17-01589R1 } \\
\hline Full Title: & \multicolumn{2}{|c|}{$\begin{array}{l}\text { Kinetic analysis of the thermal decomposition of liquid ammonium nitrate based on } \\
\text { thermal analysis and detailed reaction simulations }\end{array}$} \\
\hline Article Type: & \multicolumn{2}{|l|}{ S.I. : CEEC-TAC4 } \\
\hline Corresponding Author: & \multicolumn{2}{|l|}{$\begin{array}{l}\text { Yu-ichiro Izato, Ph. D } \\
\text { Yokohama National University } \\
\text { Yokohama, JAPAN }\end{array}$} \\
\hline \multicolumn{3}{|l|}{$\begin{array}{l}\text { Corresponding Author Secondary } \\
\text { Information: }\end{array}$} \\
\hline Corresponding Author's Institution: & \multicolumn{2}{|l|}{ Yokohama National University } \\
\hline \multicolumn{3}{|l|}{$\begin{array}{l}\text { Corresponding Author's Secondary } \\
\text { Institution: }\end{array}$} \\
\hline First Author: & \multicolumn{2}{|l|}{ Yu-ichiro Izato, Ph. D } \\
\hline \multicolumn{3}{|l|}{ First Author Secondary Information: } \\
\hline \multirow[t]{2}{*}{ Order of Authors: } & \multicolumn{2}{|l|}{ Yu-ichiro Izato, Ph. D } \\
\hline & \multicolumn{2}{|l|}{ Atsumi Miyake, Ph.D. } \\
\hline \multicolumn{3}{|c|}{ Order of Authors Secondary Information: } \\
\hline Funding Information: & $\begin{array}{l}\text { Japan Society for the Promotion of } \\
\text { Science } \\
(17 \mathrm{H} 00844)\end{array}$ & Professor Atsumi Miyake \\
\hline Abstract: & \multicolumn{2}{|c|}{$\begin{array}{l}\text { A detailed reaction mechanism for the liquid-phase decomposition of ammonium } \\
\text { nitrate (AN) was modeled based on ab initio calculations, and this model was } \\
\text { employed to simulate heat flow curves associated with the decomposition of AN at } \\
\text { various heating rates }(1,2,4,5 \text { and } 8 \mathrm{~K} \text { min-1) over the temperature range of } 443-623 \\
\mathrm{K} \text {. A kinetic analysis using the model-free Friedman method determined the kinetic } \\
\text { triplet for AN decomposition. The predicted activation energy for the exothermic } \\
\text { decomposition had a range of approximately } 162-168 \mathrm{~kJ} \text { mol- } 1 \text { with a values between } \\
0.1 \text { and } 0.5 \text {. The activation-energy value is good agreement with the experimental one } \\
\text { of } 170 \mathrm{~kJ} \text { mol-1. The Friedman kinetic model was used to predict the time to maximum } \\
\text { rate under adiabatic conditions (TMRad) at various initial temperatures, and these } \\
\text { values were compared to the TMRad values obtained directly using the detailed } \\
\text { reaction mechanism. Accurate predictions for TMRad were obtained at initial } \\
\text { temperatures below } 623 \mathrm{~K} \text {. The difference between the TMRad values obtained from } \\
\text { the thermal analysis and detailed reaction models at } 823 \mathrm{~K} \text { was larger than one order } \\
\text { of magnitude. It was also found that the dominant decomposition mechanism changes } \\
\text { from ionic to radical with increasing temperature, and this explains the difference in the } \\
\text { TMRad values at } 823 \mathrm{~K} \text {. }\end{array}$} \\
\hline Response to Reviewers: & \multicolumn{2}{|l|}{ Please see attachment. } \\
\hline
\end{tabular}




\title{
Kinetic analysis of the thermal decomposition of liquid ammonium nitrate based on thermal analysis and detailed reaction simulations
}

\author{
Yu-ichiro Izato \\ Graduate school of Environment and Information Sciences, Yokohama National \\ University, 79-7 Tokiwadai, Hodogaya-ku, Yokohama, Kanagawa 240-8501, \\ Japan \\ Phone: +81-45-339-3981 \\ E-mail: izato-yuichiro-hk@ynu.jp
}

\begin{abstract}
Atsumi Miyake
Institute of Advanced Sciences, Yokohama National University, 79-5, Tokiwadai, Hodogaya, Yokohama, Kanagawa 240-8501, Japan
\end{abstract}

\begin{abstract}
A detailed reaction mechanism for the liquid-phase decomposition of ammonium nitrate (AN) was modeled based on ab initio calculations, and this model was employed to simulate heat flow curves associated with the decomposition of $\mathrm{AN}$ at various heating rates $(1,2$, 4,5 and $8 \mathrm{~K} \mathrm{~min}^{-1}$ ) over the temperature range of $443-623 \mathrm{~K}$. A kinetic analysis using the modelfree Friedman method determined the kinetic triplet for AN decomposition. The predicted activation energy for the exothermic decomposition had a range of approximately $162-168 \mathrm{~kJ}$ mol $^{-1}$ with $\alpha$ values between 0.1 and 0.5 . The activation-energy value is good agreement with the experimental one of $170 \mathrm{~kJ} \mathrm{~mol}^{-1}$. The Friedman kinetic model was used to predict the time to maximum rate under adiabatic conditions $\left(\mathrm{TMR}_{\mathrm{ad}}\right)$ at various initial temperatures, and these values were compared to the $\mathrm{TMR}_{\mathrm{ad}}$ values obtained directly using the detailed reaction mechanism. Accurate predictions for $\mathrm{TMR}_{\mathrm{ad}}$ were obtained at initial temperatures below $623 \mathrm{~K}$. The difference between the $\mathrm{TMR}_{\mathrm{ad}}$ values obtained from the thermal analysis and detailed reaction models at $823 \mathrm{~K}$ was larger than one order of magnitude. It was also found that the dominant decomposition mechanism changes from ionic to radical with increasing temperature, and this explains the difference in the TMR ${ }_{a d}$ values at $823 \mathrm{~K}$.
\end{abstract}

Keywords ammonium nitrate, thermal decomposition, kinetics analysis, time to maximum rate $\left(T M R_{a d}\right)$ 


\section{Intorduction}

Ammonium nitrate (AN) is widely used as a fertilizer ingredient because it is relatively inexpensive. Unfortunately, tragic accidental explosions involving AN have occurred in the past [1-4], including an incident at a West Fertilizer Company storage facility in Texas in 2013 that killed 14 and injured 260 [4]. Following this accident and others, the use and storage of AN have been strictly regulated. This background emphasizes the need to improve our ability to prevent accidental AN explosions. AN is also used as an oxidizer in industrial explosives because it releases almost $100 \%$ gaseous products upon reaction and has a positive oxygen balance $(+20.0 \mathrm{~g}$ $\left.\mathrm{g}^{-1}\right)$. In addition, AN has been considered as an alternative to ammonium perchlorate as a solid rocket propellant oxidizer [5]. However, the poor combustion properties of AN, including low ignitability and sluggish burning rates under low pressure conditions, have prevented the application of AN-based propellants to date. As a result, there have been many studies aimed at improving the combustion characteristics of AN in combination with various catalysts or fuels [512]. Despite this prior work, the combustion properties of AN-based propellants still require improvement.

Based on the above, it is evident that both the chemical and physical stability of AN must be increased to prevent unintended explosions during storage while, in contrast, good ignitability and high burning rates are needed to develop AN-containing propellants. To allow the safe development and use of AN-containing devices, it is important to understand both the reaction mechanisms and the kinetics controlling the combustion and decomposition properties. There have been many studies of the AN decomposition mechanism and a number of reasonable schemes have been proposed and summarized in the literature [5]. The decomposition mechanism of AN has been shown to have two potential pathways, based on ionic or radical reactions. The former path involves various ions and proceeds relatively slowly at low temperatures $(<563 \mathrm{~K})[1$, 13], while the latter involves active radicals, proceeds more rapidly, and is predominant at high temperatures (> $563 \mathrm{~K}$ ) [13]. It is known that AN melts at $442 \mathrm{~K}$ and begins to decompose after it melts. The first step of the low temperature decomposition process involves the dissociation of $\mathrm{NH}_{4} \mathrm{NO}_{3}$ $\left(\mathrm{NH}_{4}{ }^{+}\right.$and $\mathrm{NO}_{3}{ }^{-}$) into $\mathrm{NH}_{3}$ and $\mathrm{HNO}_{3}$. The next step involves the self-decomposition of $\mathrm{HNO}_{3}$ into $\mathrm{NO}_{2}{ }^{+}, \mathrm{NO}_{3}{ }^{-}$and $\mathrm{H}_{2} \mathrm{O}$, followed by the oxidation of $\mathrm{NH}_{3}$ by the $\mathrm{NO}_{2}{ }^{+}$[1]. Park and Lin [14] and Skarlis et al. [15] have also proposed another decomposition path that proceeds via $\mathrm{NH}_{3} \mathrm{OH}^{+}$, while Manelis et al. [8] have suggested that $\mathrm{HNO}_{3}$ oxidizes $\mathrm{NH}_{4}{ }^{+}$directly. In systems with a large excess of $\mathrm{HNO}_{3}$, the predominant reaction changes to oxidation by $\mathrm{N}_{2} \mathrm{O}_{5}$. Our previous work [16] analyzed the ionic decomposition of $\mathrm{AN}$ in the liquid phase, using computations based on quantum mechanics to confirm the identity of products observed in past experimental studies. During these calculations, the CBS-QB3//wB97XD/6-311++G(d,p) method [17, 18] was employed. It was found that one of the most reasonable reaction pathways is $\mathrm{HNO}_{3}+\mathrm{NH}_{4}{ }^{+} \rightarrow \mathrm{NH}_{3} \mathrm{NO}_{2}{ }^{+}+\mathrm{H}_{2} \mathrm{O}$ followed by $\mathrm{NH}_{3} \mathrm{NO}_{2}{ }^{+}+\mathrm{NO}_{3}{ }^{-} \rightarrow \mathrm{NH}_{2} \mathrm{NO}_{2}+\mathrm{HNO}_{3}$. The other path is $\mathrm{HNO}_{3}+\mathrm{HNO}_{3} \rightarrow \mathrm{N}_{2} \mathrm{O}_{5}+$ $\mathrm{H}_{2} \mathrm{O}$ followed by $\mathrm{N}_{2} \mathrm{O}_{5}+\mathrm{NH}_{3} \rightarrow \mathrm{NH}_{2} \mathrm{NO}_{2}+\mathrm{H}_{2} \mathrm{O}$, after which the nitramide $\left(\mathrm{NH}_{2} \mathrm{NO}_{2}\right)$ decomposes to $\mathrm{N}_{2} \mathrm{O}$ and $\mathrm{H}_{2} \mathrm{O}$. The thermal decomposition of $\mathrm{AN}$ in the liquid phase can therefore be summarized as $\mathrm{NH}_{4}{ }^{+}+\mathrm{NO}_{3}{ }^{-}(\mathrm{AN}) \rightarrow \mathrm{N}_{2} \mathrm{O}+2 \mathrm{H}_{2} \mathrm{O}$. Although the proposed details of the AN decomposition reaction differ among researchers, the overall condensed-phase decomposition may be expressed as $\mathrm{NH}_{4} \mathrm{NO}_{3} \rightarrow \mathrm{N}_{2} \mathrm{O}+2 \mathrm{H}_{2} \mathrm{O}$. The gases resulting from the ionic reactions are primarily $\mathrm{N}_{2} \mathrm{O}$ and $\mathrm{H}_{2} \mathrm{O}$, with $\mathrm{N}_{2}$ as a minor product $[19,20]$. As the temperature increases, the ionic decomposition of $\mathrm{AN}$ is thought to be overtaken by high temperature radical decomposition. and Brower et al. [13] suggested a mechanism for the radical reaction of AN at elevated temperatures (> $563 \mathrm{~K}$ ). In this mechanism, $\mathrm{AN}$ initially dissociates into $\mathrm{HNO}_{3}$ and $\mathrm{NH}_{3}$, followed by homolytic cleavage of the $\mathrm{HO}-\mathrm{N}$ bond in $\mathrm{HNO}_{3}$. Following this cleavage, a high-speed radical chain reaction develops and yields large amounts of gaseous $\mathrm{N}_{2}, \mathrm{NO}$ and $\mathrm{H}_{2} \mathrm{O}$. Since the activation energy for the homolysis of $\mathrm{HNO}_{3}$ is very high (approximately $190 \mathrm{~kJ} \mathrm{~mol}^{-1}$ ), this represents the rate controlling step and radical reactions do not play an important role at low temperatures $(<563$ K) [13].

Thermal analysis is a powerful tool for the investigation of the decomposition kinetics of various materials. Kinetic analysis can have either a theoretical or a practical purpose. The theoretical purpose of kinetic analysis is typically interpretation of experimentally-determined kinetic triplets, while the most common practical purpose is the prediction of process rates and material lifetimes. The goal of kinetic analysis is to parameterize the process rate in terms of variables such as temperature, extent of conversion and, in some cases, pressure. Parameterization is accomplished by evaluating the parameters of equations that describe the effects of variables on the process rate. To date, there have been many studies of AN decomposition kinetics. Kinetic analysis based on thermal analysis is a useful means of examining the kinetics of AN 
decomposition, and much research regarding AN has been performed under various conditions, with the results summarized in reference [21]. The AN thermal decomposition kinetics depend on several factors, including temperature, pressure, isothermal or non-isothermal conditions, extent of reaction, catalysis and reactive species. The activation energies reported by various researchers range of 30-200 $\mathrm{kJ} \mathrm{mol}^{-1}$, depending on the specific sample analyzed and the experimental methods. Willis et al. [19] investigated the kinetics of decomposition of liquid AN (AN (L) $\rightarrow \mathrm{N}_{2} \mathrm{O}$ $\left.(\mathrm{G})+2 \mathrm{H}_{2} \mathrm{O}(\mathrm{G})\right)$ in the temperature range 498 to $548 \mathrm{~K}$ using a flow reactor, and also reported the activation energy of liquid phase decomposition is $170 \mathrm{~kJ} \mathrm{~mol}^{-1}$.

In the present work, we examined both the theoretical and practical purposes of kinetic analysis based on detailed reaction simulations. The specific goals were: (i) to simulate the AN decomposition thermal behavior based on a detailed reaction model, (ii) to analyze the kinetics using the model-free Friedman method so as to compare the kinetics obtained in reference [19], and (iii) to simulate thermal behavior at various temperatures based on the kinetic analysis and detailed reaction model. Kinetic analysis can also simulate the thermal behaviors of materials under extreme conditions that cannot readily be achieved during thermal analysis. The resulting predictions are reliable only when sound kinetic model involving adequate kinetic parameters (the activation energy, the pre-exponential factor, and the reaction are used. This work verifies the kinetics based on the model-free Friedman method, and compares the predictions from the kinetic analysis and the detailed reaction simulation.

\section{Computational}

\section{Detailed reaction model}

The detailed reaction model consists of two parts: a collection of elementary reactions with their rate coefficients and thermodynamic data. The present work employed the YNU-L 1.0 model, consisting of various kinetic parameters (a total of 54 reactions) and the thermodynamic data for 29 species.

The rate coefficient, $k_{\mathrm{TST}}$, of the generic reaction $\mathrm{A}+\mathrm{B} \rightarrow$ products can be calculated on the basis of traditional transition state theory (TST) using the well-known formula $k_{\mathrm{TST}}=$ $\frac{k_{\mathrm{B}} T}{h} \frac{Q_{\mathrm{TS}}}{\prod Q_{\mathrm{reac}}} \exp \left(\frac{-\Delta E_{0}}{R T}\right)$, where $k_{\mathrm{B}}$ is the Boltzmann constant, $T$ is the temperature, $h$ is the Planck constant, $Q_{\mathrm{i}}$ is the partition function of the reactant and transition state (TS), $\Delta E_{0}$ is the energy barrier to activation, and $R$ is the universal gas constant. The TST provides rate of an elementary reaction, if we obtain $Q_{\mathrm{i}}$ and $\Delta E_{0}$ of TS and reactants. Both of $Q_{\mathrm{i}}$ and $\Delta E_{0}$ can be computed by quantum chemical calculation. In our previous work [16], liquid-phase reactions were investigated

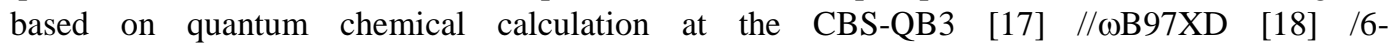
$311++\mathrm{G}(\mathrm{d}, \mathrm{p}) / \mathrm{SCRF}=$ (solvent $=$ water $)$ level of theory and the associated potential energy diagrams, reactants, and TS structures were identified and investigated. The TS is a surface in configuration space that divides reactants from products and passes through the saddle point of the potential-energy surface. In this study, we calculated $k_{\mathrm{TST}}$ of reactions identified in our previous study $[16,22]$. Variational TS theory (VTST) was applied to the analysis of dissociation reactions without barriers. The VTST is distinguished by varying the definition of the TS to minimize the one-way rate coefficient. These calculations were aided by the GPOP software package developed by Miyoshi [23]. Radical recombinations and proton transfers with no barriers were modeled as diffusion-limited reactions with rate coefficients set at $10^{9} \mathrm{~cm}^{3} \mathrm{~mol}^{-1} \mathrm{~s}^{-1}$. The important reactions associated with the decomposition of liquid-phase AN and the associated kinetic parameters for the modified Arrhenius equation are provided in Table 1 (for the ionic pathway) and Table 2 (for the radical pathway).

Thermal correction, entropy $\left(S_{\text {liq }}\right)$ and heat capacity $\left(C_{P}\right)$ values were calculated from the $Q_{\mathrm{i}}$ using statistical machinery, employing the GPOP software package [23]. The heats of formation for gas-phase molecules $\left(\Delta_{f} H_{\text {gas }}^{\circ}\right)$ were calculated by the traditional atomization method (ARM-1) [24] combined with the G4 [25]/SCRF = (solvent = water) level of theory using the Gaussian 09 program package [26]. Solvent effects were included by applying the self-consistent reaction field (SCRF) and polarizable continuum model (PCM) options within the program when investigating the liquid species in molten AN. Unfortunately, the solvent effect of molten AN is not known. The dielectric constant for solid AN has been reported to be approximately 40 [-] at $383 \mathrm{~K}$ [27], and it is known that this value tends to increase along with temperature. Thus, molten AN could be considered as a highly polar solvent, so we employed the water solvation effect as a substitute for molten AN. It is noted that the water solvation effect should be replaced with a more adequate 
solvation effect in future work. In the interim, we believe that the use of water solvation is a practical means of obtaining some insights regarding the liquid-phase decomposition of AN .

The standard heat of formation for a compound in solution is obtained from the gas-phase heat of formation and the enthalpy of solvation at $298.15 \mathrm{~K}$, as in the following two equations.

$$
\begin{aligned}
& \Delta_{f} H_{\text {liq }}^{\circ}=\Delta_{f} H_{\text {gas }}^{\circ}+\Delta_{\text {solv }} H^{\circ} \\
& \Delta_{\text {solv }} H^{\circ}=H_{\text {liq,calc }}-H_{\text {gas,calc }}
\end{aligned}
$$

Here, $\Delta_{f} H_{\text {liq }}^{\circ}$ is the heats of formation for liquid phase compounds, $\Delta_{f} H_{g a s}^{\circ}$ is the heats of formation for gas phase compounds, $\Delta_{\text {solv }} H^{\circ}$ is the solvation enthalpy, and $H_{\text {liq, calc }}$ and $H_{\text {gas,calc }}$ are the heats of formation at $298.15 \mathrm{~K}$ calculated directly using G4 methods. Table 3 lists the thermodynamic data for liquid-phase compounds obtained at the G4 level of theory.

Table 1. Important reactions and associated rate coefficients employed during the kinetic

\begin{tabular}{|c|c|c|c|c|}
\hline \multirow{2}{*}{ No. } & \multirow{2}{*}{ Reaction } & \multicolumn{3}{|c|}{$k=A \cdot T^{n} \exp \left(-\Delta E_{a} / R T\right)$} \\
\hline & & $A^{a}$ & $n$ & $\Delta E_{a}^{b}$ \\
\hline 1 & $\mathrm{AN} \rightleftharpoons \mathrm{NH}_{3}+\mathrm{HNO}_{3}$ & $3.03 \times 10^{16}$ & -0.95 & 41.1 \\
\hline 2 & $\mathrm{AN} \rightleftharpoons \mathrm{NH}_{4}^{+}+\mathrm{NO}_{3}^{-}$ & $6.50 \times 10^{20}$ & -2.01 & 65.1 \\
\hline 3 & $\mathrm{NH}_{3}+\mathrm{HNO}_{3} \rightleftharpoons \mathrm{NH}_{2} \mathrm{NO}_{2}+\mathrm{H}_{2} \mathrm{O}$ & $1.22 \times 10^{1}$ & 3.11 & 168.7 \\
\hline 4 & $\mathrm{NH}_{4}^{+}+\mathrm{HNO}_{3} \rightleftharpoons \mathrm{NH}_{3} \mathrm{NO}_{2}^{+}+\mathrm{H}_{2} \mathrm{O}$ & $4.50 \times 10^{2}$ & 3.66 & 123.1 \\
\hline 5 & $\mathrm{AN}+\mathrm{HNO}_{3} \rightleftharpoons \mathrm{NH}_{2} \mathrm{NO}_{2}+\mathrm{HNO}_{3}+\mathrm{H}_{2} \mathrm{O}$ & $1.16 \times 10^{1}$ & 3.58 & 123.1 \\
\hline 6 & $\mathrm{HNO}_{3}+\mathrm{HNO}_{3} \rightleftharpoons \mathrm{N}_{2} \mathrm{O}_{5}+\mathrm{H}_{2} \mathrm{O}$ & $2.19 \times 10^{2}$ & 3.20 & 89.9 \\
\hline 7 & $\mathrm{NH}_{3}+\mathrm{N}_{2} \mathrm{O}_{5} \rightleftharpoons \mathrm{NH}_{2} \mathrm{NO}_{2}+\mathrm{HNO}_{3}$ & $1.72 \times 10^{2}$ & 2.98 & 22.2 \\
\hline 8 & $\mathrm{NH}_{4}^{+}+\mathrm{N}_{2} \mathrm{O}_{5} \rightleftharpoons \mathrm{NH}_{3} \mathrm{NO}_{2}^{+}+\mathrm{HNO}_{3}$ & $5.20 \times 10^{3}$ & 3.26 & 88.5 \\
\hline 9 & $\mathrm{NH}_{3} \mathrm{NO}_{2}{ }^{+}+\mathrm{NO}_{3}^{-} \rightleftharpoons \mathrm{NH}_{2} \mathrm{NO}_{2}+\mathrm{HNO}_{3}$ & $1.00 \times 10^{9}$ & 0.0 & 0.0 \\
\hline 10 & $\mathrm{NH}_{3} \mathrm{NO}_{2}^{+}+\mathrm{NH}_{3} \rightleftharpoons \mathrm{NH}_{2} \mathrm{NO}_{2}+\mathrm{NH}_{4}^{+}$ & $1.00 \times 10^{9}$ & 0.0 & 0.0 \\
\hline 11 & $\mathrm{HNO}_{3}+\mathrm{HONO} \rightleftharpoons \mathrm{t}-\mathrm{ONONO}_{2}+\mathrm{H}_{2} \mathrm{O}$ & $9.45 \times 10^{-1}$ & 3.60 & 5.3 \\
\hline 12 & $\mathrm{t}-\mathrm{ONONO}{ }_{2} \rightleftharpoons \mathrm{NO}_{2}+\mathrm{NO}_{2}$ & $2.95 \times 10^{12}$ & 0.17 & 33.1 \\
\hline 13 & $\mathrm{t}-\mathrm{ONONO}_{2}+\mathrm{NH}_{3} \rightleftharpoons \mathrm{NH}_{2} \mathrm{NO}+\mathrm{HNO}_{3}$ & $1.00 \times 10^{9}$ & 0.0 & 0.0 \\
\hline 14 & $\mathrm{t}-\mathrm{ONONO}_{2}+\mathrm{NH}_{4}^{+} \rightleftharpoons \mathrm{NH}_{3} \mathrm{NO}^{+}+\mathrm{HNO}_{3}$ & $1.44 \times 10^{2}$ & 3.21 & 60.6 \\
\hline 15 & $\mathrm{NH}_{3} \mathrm{NO}^{+}+\mathrm{NO}_{3}{ }^{-} \rightleftharpoons \mathrm{NH}_{2} \mathrm{NO}+\mathrm{HNO}_{3}$ & $1.00 \times 10^{9}$ & 0.0 & 0.0 \\
\hline 16 & $\mathrm{NH}_{3} \mathrm{NO}^{+}+\mathrm{NH}_{3} \rightleftharpoons \mathrm{NH}_{2} \mathrm{NO}+\mathrm{NH}_{4}^{+}$ & $1.00 \times 10^{9}$ & 0.0 & 0.0 \\
\hline 17 & $\mathrm{NH}_{2} \mathrm{NO}_{2} \rightleftharpoons \mathrm{NHNO}_{2} \mathrm{H}$ & $2.10 \times 10^{-1}$ & 3.20 & 128.7 \\
\hline 18 & $\mathrm{NH}_{2} \mathrm{NO}_{2}+\mathrm{H}_{2} \mathrm{O} \rightleftharpoons \mathrm{NHNO}_{2} \mathrm{H}+\mathrm{H}_{2} \mathrm{O}$ & 1.47 & 3.09 & 53.6 \\
\hline 19 & $\mathrm{NHNO}_{2} \mathrm{H} \rightleftharpoons \mathrm{N}_{2} \mathrm{O}+\mathrm{H}_{2} \mathrm{O}$ & $8.77 \times 10^{9}$ & 1.23 & 134.9 \\
\hline 20 & $\mathrm{NHNO}_{2} \mathrm{H}+\mathrm{H}_{2} \mathrm{O} \rightleftharpoons \mathrm{N}_{2} \mathrm{O}+\mathrm{H}_{2} \mathrm{O}+\mathrm{H}_{2} \mathrm{O}$ & 5.46 & 3.58 & 99.8 \\
\hline 21 & $\mathrm{NHNO}_{2} \mathrm{H}+\mathrm{NO}_{3}^{-} \rightleftharpoons \mathrm{N}_{2} \mathrm{O}+\mathrm{H}_{2} \mathrm{O}+\mathrm{NO}_{3}^{-}$ & $7.52 \times 10^{2}$ & 3.41 & 35.6 \\
\hline 22 & $\mathrm{NHNO}_{2} \mathrm{H}+\mathrm{NH}_{3} \rightleftharpoons \mathrm{N}_{2} \mathrm{O}+\mathrm{H}_{2} \mathrm{O}+\mathrm{NH}_{3}$ & $2.03 \times 10^{-1}$ & 3.34 & -2.6 \\
\hline 23 & $\mathrm{H}_{3} \mathrm{O}^{+}+\mathrm{OH}^{-} \rightleftharpoons \mathrm{H}_{2} \mathrm{O}+\mathrm{H}_{2} \mathrm{O}$ & $1.00 \times 10^{9}$ & 0.0 & 0.0 \\
\hline 24 & $\mathrm{NH}_{3}+\mathrm{H}_{2} \mathrm{O} \rightleftharpoons \mathrm{NH}_{4}^{+}+\mathrm{OH}^{-}$ & $1.00 \times 10^{9}$ & 0.0 & 0.0 \\
\hline 25 & $\mathrm{NH}_{4}^{+}+\mathrm{H}_{2} \mathrm{O} \rightleftharpoons \mathrm{NH}_{3}+\mathrm{H}_{3} \mathrm{O}^{+}$ & $1.00 \times 10^{9}$ & 0.0 & 0.0 \\
\hline 26 & $\mathrm{HNO}_{3}+\mathrm{H}_{2} \mathrm{O} \rightleftharpoons \mathrm{NO}_{3}^{-}+\mathrm{H}_{3} \mathrm{O}^{+}$ & $1.00 \times 10^{9}$ & 0.0 & 0.0 \\
\hline 27 & $\mathrm{NO}_{3}^{-}+\mathrm{H}_{2} \mathrm{O} \rightleftharpoons \mathrm{HNO}_{3}+\mathrm{OH}^{-}$ & $1.00 \times 10^{9}$ & 0.0 & 0.0 \\
\hline
\end{tabular}
modeling of ionic decomposition.

${ }^{a}$ Frequency factor $A$ is given in units of $\mathrm{cm}^{3}$, mol, and $\mathrm{s}$.

${ }^{b}$ Activation energy $\Delta E_{a}$ is in units $\mathrm{kJ} \mathrm{mol}^{-1}$. 
Table 2. Reactions and associated rate coefficients employed during the kinetic modeling of radical decomposition.

\begin{tabular}{|c|c|c|c|c|}
\hline \multirow{2}{*}{ No. } & \multirow{2}{*}{ Reaction } & \multicolumn{3}{|c|}{$k$} \\
\hline & & $A^{a}$ & $n$ & $\Delta E_{a}^{b}$ \\
\hline 28 & $\mathrm{HNO}_{3} \rightleftharpoons \mathrm{NO}_{2}+\mathrm{OH}$ & $4.63 \times 10^{12}$ & 1.40 & 181.6 \\
\hline 29 & $\mathrm{NH}_{3}+\mathrm{OH} \rightleftharpoons \mathrm{NH}_{2}+\mathrm{H}_{2} \mathrm{O}$ & $9.09 \times 10^{2}$ & 3.10 & 10.3 \\
\hline 30 & $\mathrm{NH}_{3}+\mathrm{NO}_{2} \rightleftharpoons \mathrm{NH}_{2}+\mathrm{HONO}$ & 5.46 & 3.58 & 99.8 \\
\hline 31 & $\mathrm{NH}_{3}+\mathrm{NO}_{2} \rightleftharpoons \mathrm{NH}_{2}+\mathrm{HNO}_{2}$ & $1.92 \times 10^{1}$ & 3.54 & 125.1 \\
\hline 32 & $\mathrm{NH}_{2}+\mathrm{NO}_{2} \rightleftharpoons \mathrm{NH}_{2} \mathrm{NO}_{2}$ & $1.00 \times 10^{9}$ & 0.0 & 0.0 \\
\hline 33 & $\mathrm{NH}_{2}+\mathrm{NO}_{2} \rightleftharpoons \mathrm{NH}_{2} \mathrm{ONO}$ & $2.00 \times 10^{3}$ & 2.81 & -15.0 \\
\hline 34 & $\mathrm{NH}_{2} \mathrm{ONO} \rightleftharpoons \mathrm{NH}_{2} \mathrm{O}+\mathrm{NO}$ & $9.45 \times 10^{12}$ & 0.30 & 54.1 \\
\hline 35 & $\mathrm{NH}_{2}+\mathrm{NO} \rightleftharpoons \mathrm{NH}_{2} \mathrm{NO}$ & $1.00 \times 10^{9}$ & 0.0 & 0.0 \\
\hline 36 & $\mathrm{NH}_{2} \mathrm{NO} \rightleftharpoons \mathrm{NHNOH}$ & $2.15 \times 10^{-1}$ & 3.82 & 98.4 \\
\hline 37 & $\mathrm{NHNOH} \rightleftharpoons \mathrm{N}_{2}+\mathrm{H}_{2} \mathrm{O}$ & $1.76 \times 10^{11}$ & 0.89 & 99.4 \\
\hline 38 & $\mathrm{NHNOH}+\mathrm{H}_{2} \mathrm{O} \rightleftharpoons \mathrm{N}_{2}+\mathrm{H}_{2} \mathrm{O}+\mathrm{H}_{2} \mathrm{O}$ & 4.60 & 3.96 & 54.6 \\
\hline 39 & $\mathrm{NHNOH}+\mathrm{NH}_{3} \rightleftharpoons \mathrm{N}_{2}+\mathrm{H}_{2} \mathrm{O}+\mathrm{NH}_{3}$ & 6.55 & 3.65 & -1.7 \\
\hline 40 & $\mathrm{NHNOH}+\mathrm{NH}_{3} \rightleftharpoons \mathrm{N}_{2}+\mathrm{H}_{2} \mathrm{O}+\mathrm{NH}_{3}$ & 5.49 & 3.96 & 4.1 \\
\hline 41 & $\mathrm{NH}_{2} \mathrm{NO}+\mathrm{H}_{2} \mathrm{O} \rightleftharpoons \mathrm{NHNOH}+\mathrm{H}_{2} \mathrm{O}$ & $6.02 \times 10^{-3}$ & 3.79 & 40.4 \\
\hline 42 & $\mathrm{NH}_{2} \mathrm{O}+\mathrm{NO}_{2} \rightleftharpoons \mathrm{HNO}+\mathrm{HONO}$ & $3.25 \times 10^{1}$ & 2.98 & 32.6 \\
\hline 43 & $\mathrm{HNO}_{2}+\mathrm{NO}_{2} \rightleftharpoons \mathrm{HONO}+\mathrm{H}_{2} \mathrm{O}$ & $7.54 \times 10^{1}$ & 3.05 & 56.2 \\
\hline 44 & $\mathrm{HNO}_{2}+\mathrm{HNO}_{2} \rightleftharpoons \mathrm{HONO}+\mathrm{HONO}$ & $1.89 \times 10^{-4}$ & 4.42 & 21.8 \\
\hline
\end{tabular}

${ }^{a}$ Frequency factor is given in units of $\mathrm{cm}^{3}, \mathrm{~mol}$, and $\mathrm{s}$.

${ }^{b}$ Activation energy is in units $\mathrm{kJ} \mathrm{mol}^{-1}$. 
Table 3. Calculated thermodynamic values for species associated with AN decomposition.

\begin{tabular}{|c|c|c|c|c|c|c|c|c|c|}
\hline \multirow{2}{*}{ SPECIES } & \multirow{2}{*}{$\begin{array}{c}\Delta_{f} H_{l i q}^{\circ} \\
{[\mathrm{kJ} / \mathrm{mol}]}\end{array}$} & \multirow{2}{*}{$\underset{[\mathrm{J} / \mathrm{mol} \mathrm{K}]}{S_{l i q}^{\circ}}$} & \multicolumn{7}{|c|}{$\mathrm{Cp}[\mathrm{J} / \mathrm{K} \mathrm{mol}]$} \\
\hline & & & $300 \mathrm{~K}$ & 400 & 500 & 600 & 800 & 1000 & 1500 \\
\hline $\mathrm{H}_{2} \mathrm{O}$ & -257.6 & 194.5 & 33.44 & 34.02 & 34.91 & 35.95 & 38.2 & 40.57 & 45.98 \\
\hline NO & 88.1 & 205.2 & 29.16 & 29.44 & 30.00 & 30.74 & 32.26 & 33.49 & 35.30 \\
\hline $\mathrm{NO}_{2}$. & 26.6 & 239.9 & 36.95 & 39.99 & 42.95 & 45.56 & 49.45 & 51.96 & 55.08 \\
\hline $\mathrm{N}_{2} \mathrm{O}$ & 74.6 & 219.3 & 37.97 & 41.94 & 45.08 & 47.66 & 51.57 & 54.28 & 58.04 \\
\hline $\mathrm{N}_{2} \mathrm{O}_{5}$ & -6.2 & 344.9 & 91.59 & 105.27 & 115.86 & 124.01 & 135.13 & 141.87 & 150.02 \\
\hline$t \mathrm{ONONO}_{2}$ & 16.5 & 340.3 & 81.65 & 91.70 & 99.61 & 105.80 & 114.42 & 119.78 & 126.39 \\
\hline $\mathrm{HNO}_{3}$ & -154.4 & 271.1 & 52.44 & 62.13 & 69.87 & 75.90 & 84.32 & 89.80 & 97.52 \\
\hline HONO & -92.1 & 253.2 & 44.34 & 50.33 & 55.17 & 59.02 & 64.59 & 68.42 & 74.25 \\
\hline $\mathrm{HNO}_{2}$ & -68.8 & 238.1 & 38.26 & 43.51 & 48.84 & 53.59 & 61.00 & 66.19 & 73.64 \\
\hline $\mathrm{HNO}$ & 95.3 & 220.6 & 33.68 & 34.95 & 36.86 & 38.99 & 43.04 & 46.31 & 51.42 \\
\hline $\mathrm{NH}_{3}$ & -55.8 & 198.1 & 34.69 & 37.19 & 40.24 & 43.35 & 49.24 & 54.54 & 64.68 \\
\hline $\mathrm{NH}_{2}$. & 173.6 & 194.7 & 33.53 & 34.25 & 35.30 & 36.50 & 39.15 & 41.87 & 47.53 \\
\hline AN & -281.9 & 336.7 & 89.51 & 103.68 & 116.73 & 128.14 & 146.15 & 159.23 & 179.22 \\
\hline $\mathrm{NH}_{2} \mathrm{O}$ & 37.4 & 225.4 & 34.59 & 37.22 & 40.42 & 43.57 & 49.08 & 53.59 & 61.51 \\
\hline $\mathrm{NH}_{2} \mathrm{NO}_{2}$ & -24.5 & 274.0 & 57.33 & 68.90 & 78.42 & 86.04 & 97.10 & 104.69 & 116.12 \\
\hline $\mathrm{NHNO}_{2} \mathrm{H}$ & 20.3 & 273.9 & 57.38 & 69.35 & 79.07 & 86.73 & 97.70 & 105.17 & 116.40 \\
\hline $\mathrm{NH}_{2} \mathrm{ONO}$ & 76.2 & 286.8 & 65.28 & 74.46 & 82.34 & 88.89 & 98.82 & 105.91 & 116.86 \\
\hline $\mathrm{NH}_{2} \mathrm{NO}$ & 55.2 & 258.9 & 49.89 & 57.24 & 63.75 & 69.19 & 77.45 & 83.43 & 92.99 \\
\hline $\mathrm{NHNOH}$ & 62.5 & 254.6 & 46.90 & 55.15 & 62.28 & 68.11 & 76.82 & 83.02 & 92.80 \\
\hline $\mathrm{NH}(\mathrm{OH}) \mathrm{NO}$ & 50.9 & 284.3 & 65.38 & 75.05 & 83.24 & 89.92 & 99.74 & 106.59 & 117.10 \\
\hline HNOHNO & 96.6 & 263.8 & 58.06 & 68.60 & 77.85 & 85.53 & 96.98 & 104.94 & 116.73 \\
\hline $\mathrm{N}_{2}$ & -2.4 & 191.5 & 29.11 & 29.20 & 29.47 & 29.93 & 31.16 & 32.37 & 34.48 \\
\hline $\mathrm{OH} \cdot$ & 24.4 & 178.2 & 29.1 & 29.10 & 29.12 & 29.19 & 29.58 & 30.26 & 32.30 \\
\hline $\mathrm{H}_{3} \mathrm{O}^{+}$ & -107.2 & 198.8 & 35.41 & 38.05 & 41.00 & 43.92 & 49.39 & 54.35 & 64.17 \\
\hline $\mathrm{NH}_{4}{ }^{+}$ & -53.0 & 191.5 & 34.63 & 38.14 & 43.01 & 48.19 & 57.96 & 66.41 & 81.74 \\
\hline $\mathrm{NH}_{3} \mathrm{NO}_{2}{ }^{+}$ & 126.5 & 284.7 & 63.97 & 75.70 & 86.09 & 94.92 & 108.64 & 118.67 & 134.43 \\
\hline $\mathrm{NH}_{3} \mathrm{NO}^{+}$ & 163.2 & 278.7 & 61.69 & 69.28 & 75.84 & 81.53 & 90.95 & 98.47 & 111.46 \\
\hline $\mathrm{NO}_{3}{ }^{-}$ & -184.0 & 245.5 & 44.43 & 52.29 & 58.81 & 63.85 & 70.54 & 74.43 & 78.95 \\
\hline $\mathrm{OH}^{-}$ & -96.5 & 172.3 & 29.10 & 29.10 & 29.13 & 29.21 & 29.62 & 30.34 & 32.40 \\
\hline
\end{tabular}

\section{Detailed reaction simulation}

The YNU-L 1.0 mechanism was employed to simulate the heat flow curves for AN decomposition under non-isothermal conditions in an adiabatic reactor (at constant enthalpy and volume). These calculations were performed with the CHEMKIN-PRO software package 
[28]. The initial density was set to $1.725 \mathrm{~g} \mathrm{~cm}^{-3}$, which is the density of pure liquid AN [5, 6], and the decomposition reactions were simulated at heating rates of $1,2,4,5$ and $8 \mathrm{~K} \mathrm{~min}^{-1}$ (the heating rates typically used in thermal analysis) from 443 to $623 \mathrm{~K}$. The resulting heat flow curves were investigated using the Friedman method as showed below.

The YNU-L 1.0 mechanism was also employed to predict the temperature rise in an adiabatic reactor (at constant enthalpy and volume) when applying initial temperatures of 423 , 523,623 and $823 \mathrm{~K}$. The temperature rise data obtained in this manner were compared to those generated from kinetic analysis based on the Friedman method.

\section{Kinetic analysis and thermal behavior prediction}

The basic equation for kinetic analysis is:

$\frac{d \alpha}{d t}=A(\alpha) \exp \left(-\frac{E(\alpha)}{R T(t)}\right) f(\alpha)$

where $\alpha$ is the reaction progress, $t$ is the time, $f(\alpha)$ is the reaction model, $A(\alpha)$ is the preexponential factor (note that both $f(\alpha)$ and $A(\alpha)$ are functions of the reaction progress), $R$ is the gas constant, $T$ is the temperature of the materials ( $T$ is constant in isothermal tests or a function of time in non-isothermal tests) and $E(\alpha)$ is the apparent activation energy.

The kinetic procedure employed in this study was based on the differential iso-conversion method of Friedman [29] and Ozawa [30]. The formula associated with the Friedman method (Eq. (4)) is obtained by the rearrangement of Eq. (3).

$\ln \left(\frac{d \alpha}{d t}\right)=\ln A(\alpha) f(\alpha)-\frac{E(\alpha)}{R T(t)}$

The values of $\alpha$ and $d \alpha / d t$ are determined from thermal analysis based on the following relationships.

$\alpha=\frac{\int_{t_{0}}^{t}(S(t)-B(t)) d t}{\int_{t_{0}}^{t_{\text {end }}}(S(t)-B(t)) d t}$

$\frac{d \alpha}{d t}=\frac{S(t)-B(t)}{\int_{t_{0}}^{t} \text { end }(S(t)-B(t)) d t}$

Here, $S(t)$ is a differential-type signal obtained from thermal analysis techniques such as differential scanning calorimetry (DSC) or differential thermogravimetric analysis (DTG) and $B(t)$ is the $S(t)$ baseline. For a given set of $d \alpha / d t$ values, a plot of $\ln (d \alpha / d t)$ values acquired at different heating rates as a function of $1 / T$ can be fitted to a straight line, the slope of which gives the apparent activation energy. This method permits estimation of $E(\alpha)$ without knowing $f(\alpha)$ (model-free). The Friedman method is often used for the analysis of data obtained from scanning tests performed at a constant heating rate. However, this approach is based on differential kinetic law and therefore it can be applied to results from scanning or isothermal evaluations [29, 30]. In this study, the Friedman method was employed to elaborate the heat flow curves from detailed reaction simulations based on the YNU-L1.0 model. The AKTS thermokinetics software was used during kinetic analysis to provide a model-free Friedman kinetic model. This model simulated the adiabatic temperature rise at initial temperatures of $423,523,623$ and $823 \mathrm{~K}$, assuming a constant specific heat capacity of $1.5 \mathrm{~K} \mathrm{~g}^{-1} \mathrm{~J}^{-1}$.

\section{Results and discussions}

Figure 1 shows the heat flow curves obtained from calculations for a heating rate of $5 \mathrm{~K}$ $\min ^{-1}$ using the YNU-L1.0 model as well as the experimental results acquired using a P-DSC apparatus [20,31]. A heating furnace of the DSC can be pressurized up using any gases which is supplied from external compressed gas cylinders or gas supply lines. In our previous 
studies [20, 31], Heating funeral was pressurized by helium gas at $1.1 \mathrm{MPa}$, and the gases in furnace purged to external of it. The P-DSC results demonstrated that AN exhibits an exothermic reaction above approximately $500 \mathrm{~K}$ with evolving $\mathrm{N}_{2} \mathrm{O}, \mathrm{H}_{2} \mathrm{O}$ and minor $\mathrm{N}_{2}$ gases at pressures [20,31]. The calculated sum of the moles of $\mathrm{AN}, \mathrm{NH}_{4}{ }^{+}$and $\mathrm{NH}_{3}$, indicating the unreacted moles of AN, is plotted in Figure 2. This value begins to decrease at approximately $500 \mathrm{~K}$, based on the criteria of a $1 \%$ reduction from the initial value. AN is known to undergo exothermic decomposition between 473 and $503 \mathrm{~K}$ [5], and so this model successfully predicts the decomposition onset temperature. Figure 1 also demonstrates that the moles of the major products $\mathrm{N}_{2} \mathrm{O}$ and $\mathrm{H}_{2} \mathrm{O}$ increase beginning at this same onset temperature, and that the final quantity of $\mathrm{H}_{2} \mathrm{O}$ is twice that of $\mathrm{N}_{2} \mathrm{O}$. Omitting minor products, the reaction can be summarized as $\mathrm{AN} \rightarrow \mathrm{N}_{2} \mathrm{O}+2 \mathrm{H}_{2} \mathrm{O}$. This new model therefore predicts the same evolved gases as reported in previous studies $[19,20]$. Thus, we concluded that the YNU-L 1.0 model accurately predicted the decomposition behavior of AN, taking into account that the detailed kinetics do not include any adjustable or empirical parameters. However, the initial calculated heat flows were found to be higher than the experimental values, and the detailed model did not predict the endothermic peak in experimental DSC curve following the exothermic peak maximum. One reason for these deviations could be physical changes of the specimen, including evaporation and gasification, since AN melts at $442 \mathrm{~K}$ and begins to gasify as soon as it melts. The first step of the decomposition involves the dissociation of $\mathrm{NH}_{4} \mathrm{NO}_{3}$ into $\mathrm{NH}_{3}$ and $\mathrm{HNO}_{3}$, followed by the endothermic evaporation of $\mathrm{NH}_{3}$ and $\mathrm{HNO}_{3}: \mathrm{AN}(\mathrm{l}) \rightarrow \mathrm{NH}_{3}(\mathrm{~g})+$ $\mathrm{HNO}_{3}(\mathrm{~g})-174 \mathrm{~kJ} \mathrm{~mol}^{-1}$. Other evolved gases will also evaporate from the molten AN. These endothermic phase changes occur in the molten AN, offsetting the exothermic reaction. The YNU-L1.0 model does not include such physical changes and so the experimental heat flow data prior to the peak top will be lower than the calculated values.

Figure 3 presents the simulated heat flow curves obtained at heating rates of $1,2,4$ and $8 \mathrm{~K}$ $\mathrm{min}^{-1}$. The average heat of reaction was $1940 \pm 39 \mathrm{~J} \mathrm{~g}^{-1}$, which is higher than the value of $1182 \mathrm{~J} \mathrm{~g}^{-1}$ obtained from previous sealed DSC experiments [1]. This discrepancy is also attributed to the neglect of physical changes in the detailed kinetic model. These heat flow curves were elaborated by the Friedman method.

Figure 4 shows iso-conversion plots obtained from the heat flow curves. The $E(\alpha) / R$ value is determined from the slope of the line generated by plotting $\ln \left(\frac{d \alpha}{d t}\right)$ against $1 / T(t)$ at a given conversion rate. Figure 5 plots the activation energy $E(\alpha)$ and $\ln A(\alpha) f(\alpha)$ values as functions of the reaction progress. The kinetic triplet $(f(\alpha), E$ and $\ln A)$ in Eq. (3) should be constant, assuming a single-step reaction. However, a number of the reactions included in AN decomposition involve multiple steps that contribute to the overall reaction rate measured in thermal analysis experiments. If a process involves several steps with different activation energies, the overall reaction rate will vary with both temperature and extent of conversion.

The $E(\alpha)$ and $\ln A(\alpha) f(\alpha)$ plots in Figure 4 demonstrate that both values tend to remain constant with increasing $\alpha(0.1<\alpha<0.5)$, and $E(\alpha)$ exhibits a range of approximately $165-168 \mathrm{~kJ} \mathrm{~mol}^{-1}$. The activation energy reported for the liquid-phase thermal decomposition of $\mathrm{AN}$ is $170 \mathrm{~kJ} \mathrm{~mol}^{-1}$ [19]. The calculated activation energy is good agreement with the experimental one, and this supports the validity of the YNU-L 1.0 model.

This range of activation energy values does not match that of the key elementary reaction: $\mathrm{HNO}_{3}+\mathrm{HNO}_{3} \rightarrow \mathrm{N}_{2} \mathrm{O}_{5}+\mathrm{H}_{2} \mathrm{O}$ (R6 in Table 1 , is the rate determining step based on an analysis of the rate of production using the CHEMKIN-PRO software [28]). The rate of production analysis also found that the major reactions that follow R6 are R7, R18 and R22, and the activation energy values of these reactions do not match the apparent activation energy from the Friedman method. This result is quite natural because the apparent kinetic triplet $(f(\alpha), E$ and $\ln A)$ is influenced by every elementally reaction composed detailed kinetic model, and the model in this study is quite complicated. 


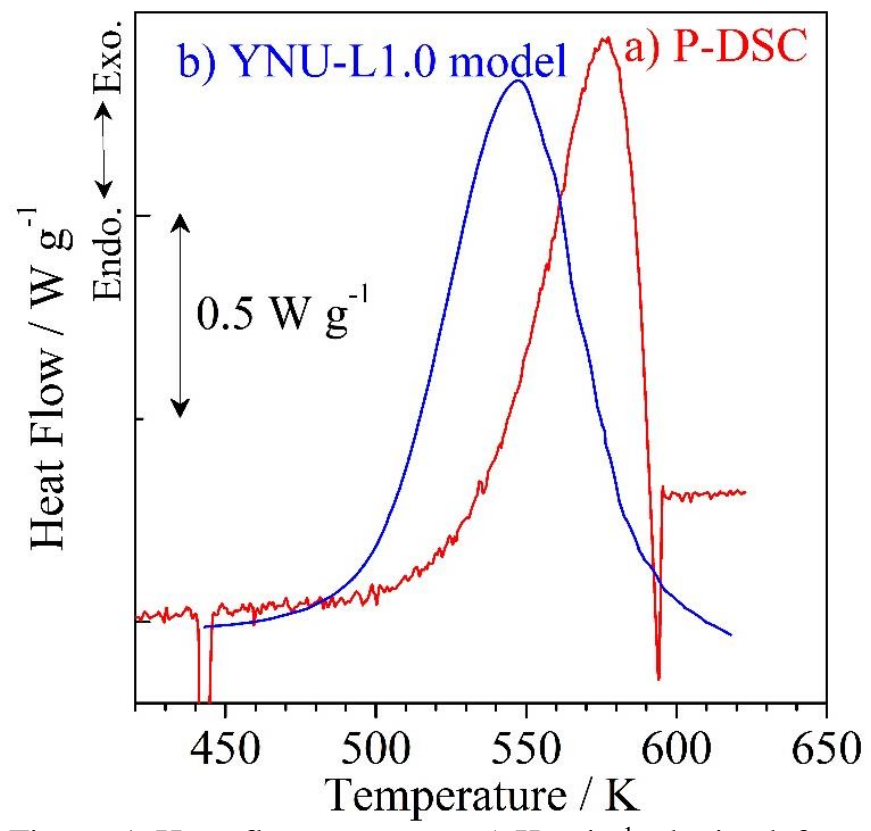

Figure 1 Heat flow curves at $5 \mathrm{~K} \mathrm{~min}^{-1}$ obtained from the a) P-DSC and b) YNU L1.0 simulations.

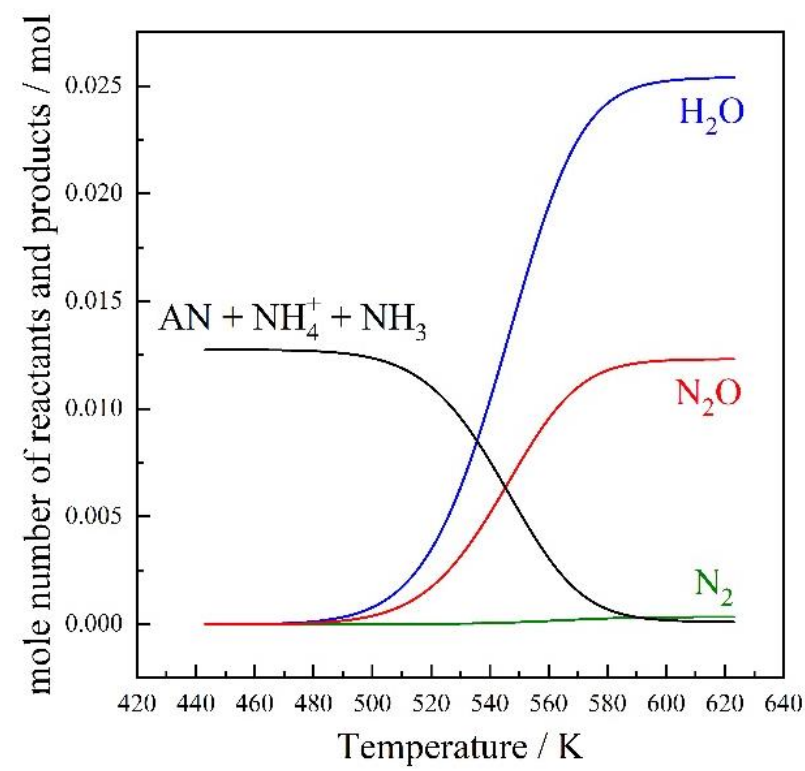

Figure 2 Variations in the AN decomposition species over temperature at a heating rate of $5 \mathrm{~K}$ $\min ^{-1}$. 


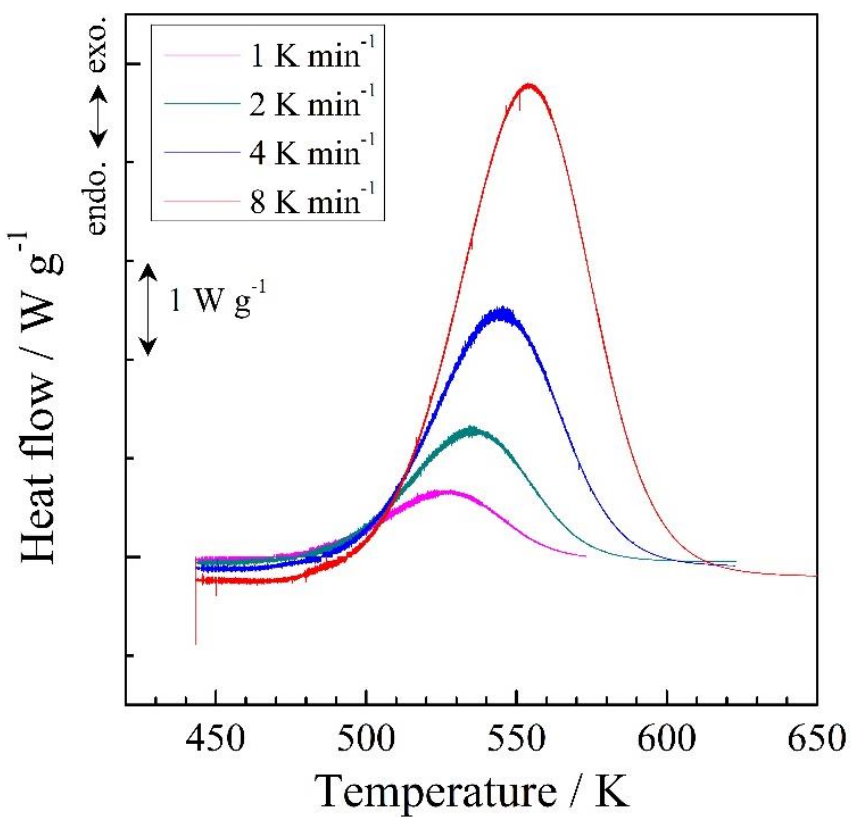

Figure 3 Heat flow curves obtained from YNU L1.0 simulations at heating rates of 1, 2, 4 and $8 \mathrm{~K} \mathrm{~min}^{-1}$.

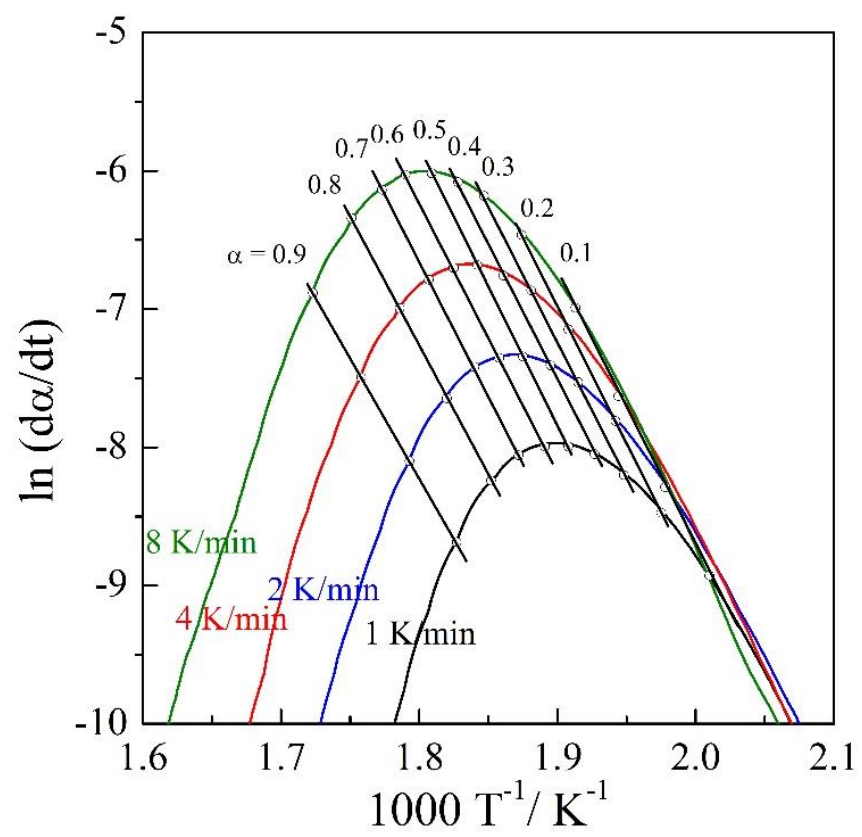

Figure 4 Iso-conversional plots of Friedman method for heat flow curves shown in Figure 2. 


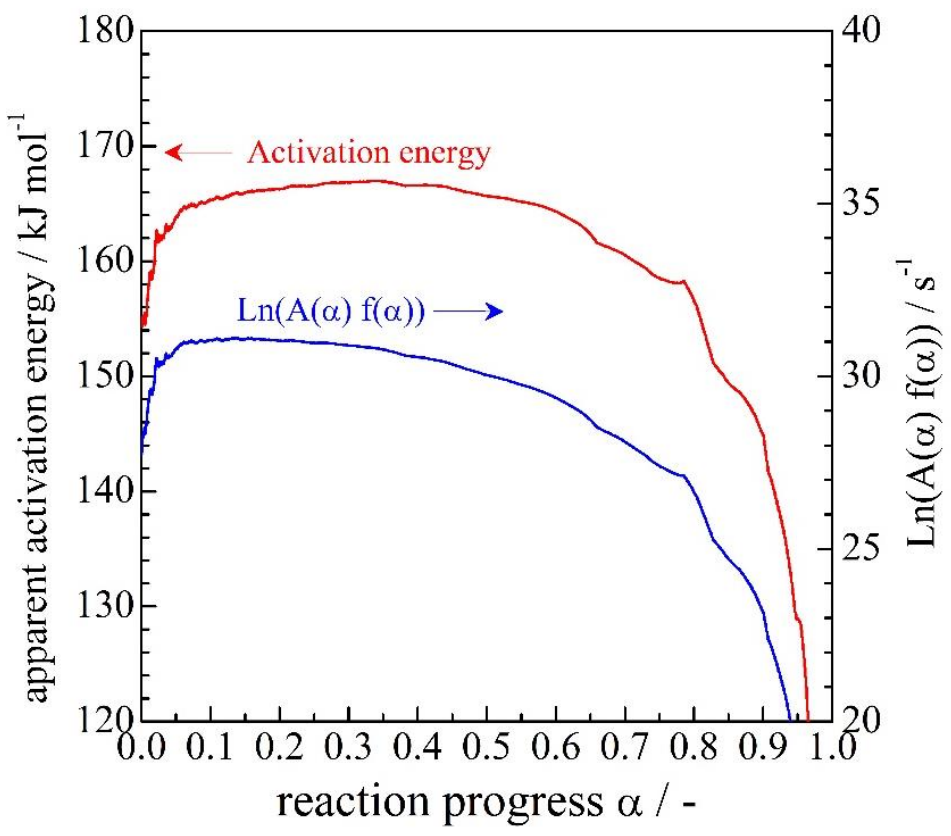

Figure 5 Activation energy as a function of the reaction progress as determined based on the Friedman method for heat flow curves from YNU-L1.0 model.

Based on kinetics, we simulated the adiabatic temperature rise obtained using initial temperatures of 423, 523, 623 and $823 \mathrm{~K}$. In addition, we simulated the thermal behavior at these same temperatures based on the YNU-L 1.0 model, employing the CHEMKIN-PRO software. Figure 5 shows the predicted temperature changes over time, which exhibit an abrupt rise in temperature following an induction time, clearly indicating a runaway reaction. This figure also shows time to maximum rate under adiabatic condition $\left(\mathrm{TMR}_{\mathrm{ad}}\right)$ values for the various initial temperatures. The YNU-L 1.0 model predictions include higher adiabatic temperature increases than those obtained from kinetic analysis. These differences are ascribed to variations in the decomposition products. The ionic condensed-phase decomposition of $\mathrm{AN}$ is known to generate $\mathrm{N}_{2} \mathrm{O}$ and $\mathrm{H}_{2} \mathrm{O}$. Figure 2 plots the generation of products at a heating rate of $5 \mathrm{~K} \mathrm{~min}^{-1}$ from 443 to $623 \mathrm{~K}$ (the associated heat flow profile is shown in Figure 1). Within this temperature range, the decomposition yields primarily $\mathrm{N}_{2} \mathrm{O}$ and $\mathrm{H}_{2} \mathrm{O}$ with only a small amount of $\mathrm{N}_{2}$. In contrast, at higher temperatures, AN decomposes to yield $\mathrm{N}_{2}$ and $\mathrm{H}_{2} \mathrm{O}$ via radical decomposition. As discussed in the Introduction, the ionic decomposition produces $\mathrm{N}_{2} \mathrm{O}$ and $\mathrm{H}_{2} \mathrm{O}$. Figure 7 plots the products obtained under the adiabatic conditions at an initial temperature of $523 \mathrm{~K}$. The mole number of $\mathrm{N}_{2} \mathrm{O}$ gradually increases as the temperature rises (the associated temperature profile is shown in Figure 5a). Following the $\mathrm{TMR}_{\mathrm{ad}}$, the temperature sharply increases and $\mathrm{N}_{2}$ gas is also evolved simultaneously. In the YNU-L 1.0 model, AN can decompose to $\mathrm{N}_{2}$ and $\mathrm{H}_{2} \mathrm{O}$ at high temperatures based on the radical reactions listed in Table 2. Due to the high chemical stability of $\mathrm{N}_{2}$, the formation of $\mathrm{N}_{2}$ produces more heat than $\mathrm{N}_{2} \mathrm{O}$ generation. The original exotherms elaborated in the model-free Friedman model (Figure 3) were primarily the result of the generation of $\mathrm{N}_{2} \mathrm{O}$ rather than $\mathrm{N}_{2}$. Thus, the net heat of reaction and adiabatic temperature changes obtained using the model-free Friedman model are smaller than those obtained from the YNU-L 1.0 model.

Although the heat of reaction for the runaway decomposition given by the model-free Friedman model is underestimated, the model does accurately predict $\mathrm{TMR}_{\mathrm{ad}}$ (within one order of magnitude of error) at initial temperatures of 423, 523 and $623 \mathrm{~K}$. Exothermic thermal decomposition to $\mathrm{N}_{2} \mathrm{O}$ and $\mathrm{H}_{2} \mathrm{O}$ increases the temperature until the runaway reaction begins and there is an abrupt rise in temperature. Figure 7 demonstrates that $\mathrm{N}_{2} \mathrm{O}$ and $\mathrm{H}_{2} \mathrm{O}$ are produced during the induction time (via ionic decomposition) rather than $\mathrm{N}_{2}$ (via radical decomposition) prior to the runaway reaction. Because the major reaction in the model-free Friedman model is the same as that during the induction reaction (representing ionic decomposition), the predictions obtained from the model-free Friedman model for the TMR values at initial temperatures of 423,523 and $623 \mathrm{~K}$ are accurate.

The difference between the $\mathrm{TMR}_{\mathrm{ad}}$ values tend to gradually increase with increasing or 
decreasing from decomposition onset-temperature of approximately $500 \mathrm{~K}$. Especially, The YNU-L1.0 model at $823 \mathrm{~K}$ is greater than one order of magnitude, as shown in Figure 6d). Figure 8 presents a plot of product formation under the adiabatic conditions at an initial temperature of $823 \mathrm{~K}$. Here, the amounts of both $\mathrm{N}_{2} \mathrm{O}$ and $\mathrm{N}_{2}$ gradually increase over time as the temperature rises (the associated temperature profile is shown in Figure $6 \mathrm{~d}$ )). More $\mathrm{N}_{2}$ is generated compared to $\mathrm{N}_{2} \mathrm{O}$ during the induction time, meaning that both ionic and radical decomposition take place during the $\mathrm{TMR}_{\mathrm{ad}} \mathrm{Span}$, and that the rate determining reaction in the radical mechanism is the homolytic cleavage of $\mathrm{HNO}_{3}$ (R28 in Table 2). The primary decomposition process changes from ionic to radical with increasing temperature and this leads to the difference in the TMR $\mathrm{Td}_{\mathrm{ad}}$ values obtained from the model-free Friedman model and YNU-L 1.0 model at $823 \mathrm{~K}$. This result demonstrates that kinetic analysis does not work well if the reaction employed in the thermal analysis is different from the reaction under the associated experimental conditions.

Thermal explosion of AN is important phenomenon to consider the safe development and use of AN-containing devices. The temporal temperature profiles in Figure 6 shows a thermal explosion behavior of AN at various initial temperatures. The temperature gradually increases during the induction period, and then the temperature sharply rises (the ignition). In the induction period at initial temperature of 523 showed in Figure 7, the mole number of $\mathrm{N}_{2} \mathrm{O}$ increases at first, and then $\mathrm{N}_{2}$ is produced. Production of $\mathrm{N}_{2} \mathrm{O}$ is the result of ionic mechanism discussed above, and production of $\mathrm{N}_{2}$ is the result of radical mechanism in Table 2. The ionic reaction of $A N$ occurs during the induction period, and $A N$ mainly decompose to $\mathrm{N}_{2} \mathrm{O}$ and $\mathrm{H}_{2} \mathrm{O}$ with increasing the temperature. As a result of increasing in temperature, the radical mechanism overwhelms the ionic reaction. Then followed chain growth reactions yield $\mathrm{N}_{2}$, $\mathrm{H}_{2} \mathrm{O}$ with larger heat of reaction. Although The YNU-L1.0 model successfully simulates a thermal explosion behavior of AN, the model does not include physical changes, evaporation and gasification. Further study is needed to improve the model and to obtain precise prediction on the thermal explosion of AN.
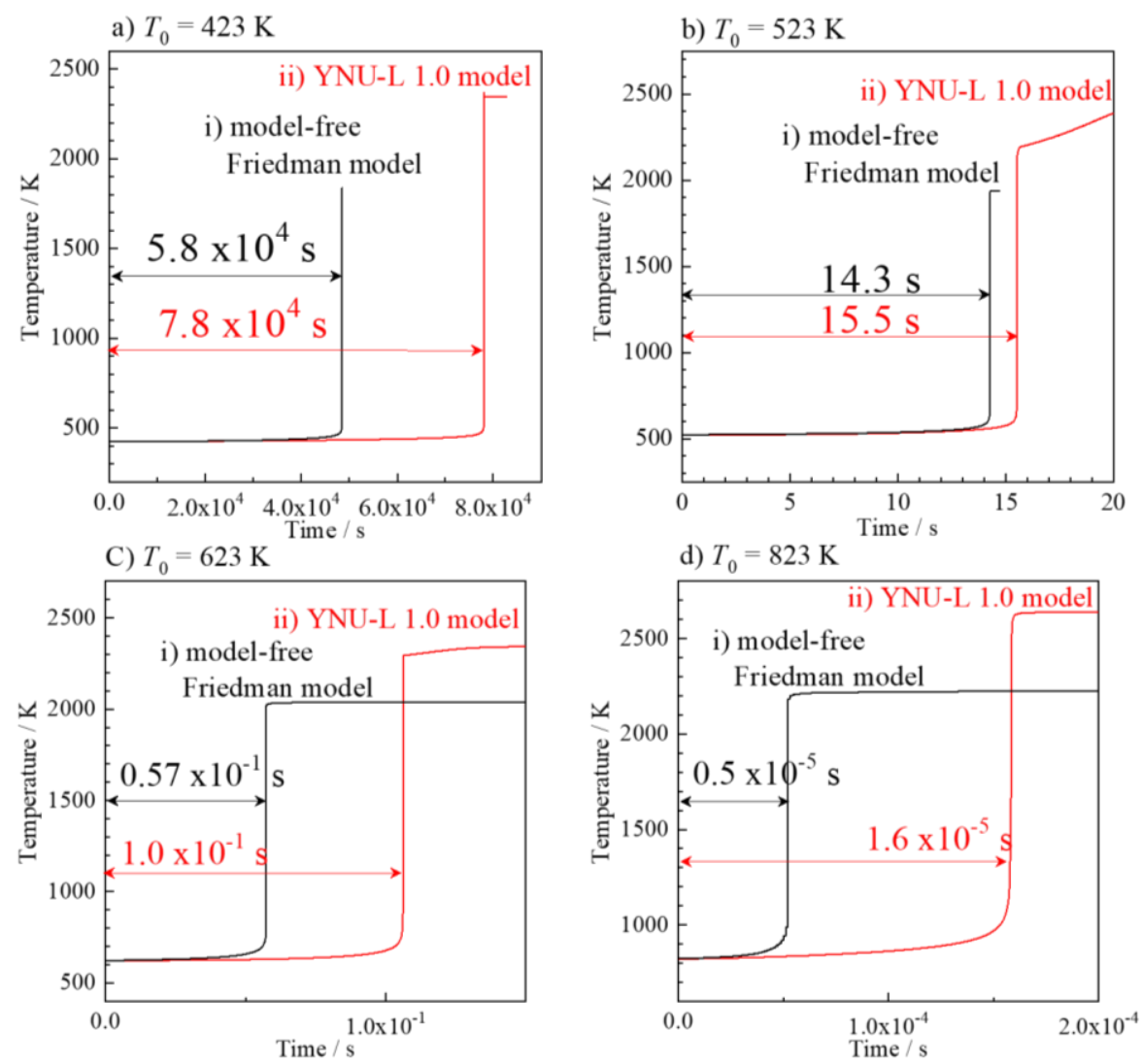

Figure 6 Temporal profiles of Temperatures simulated from i) model-free Friedman model and ii) YNU-L 1.0 model at various initial temperatures. 


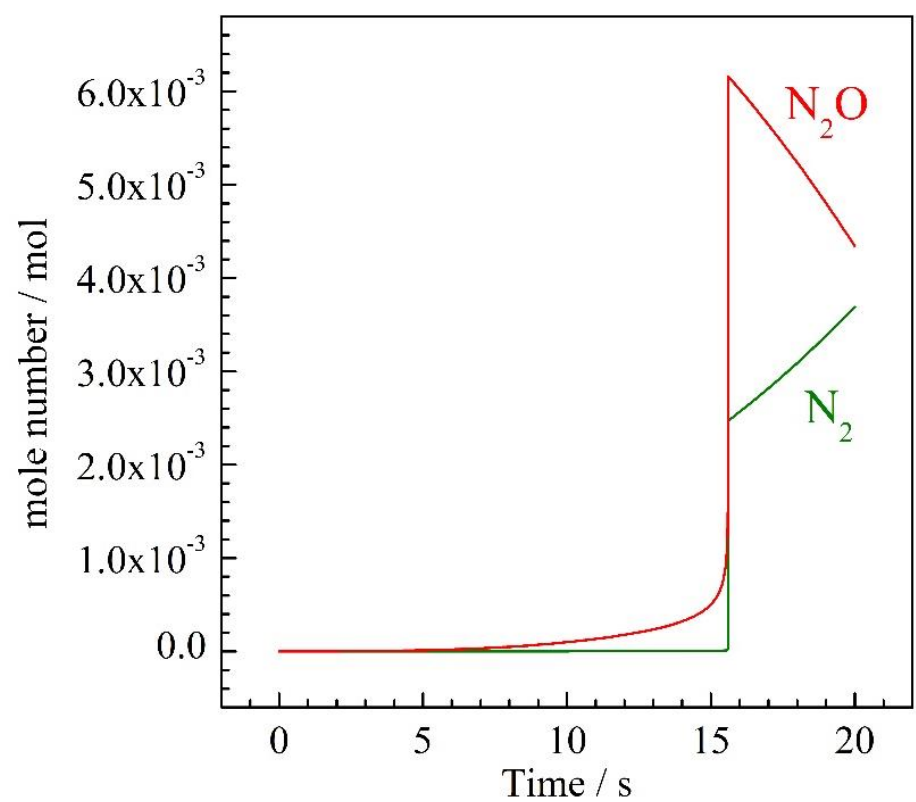

Figure 7 Temporal profiles of $\mathrm{N}_{2}$ and $\mathrm{N}_{2} \mathrm{O}$ from $\mathrm{AN}$ decomposition at initial temperature of $523 \mathrm{~K}$. This profile was simulated based on the YNU-L 1.0 model.

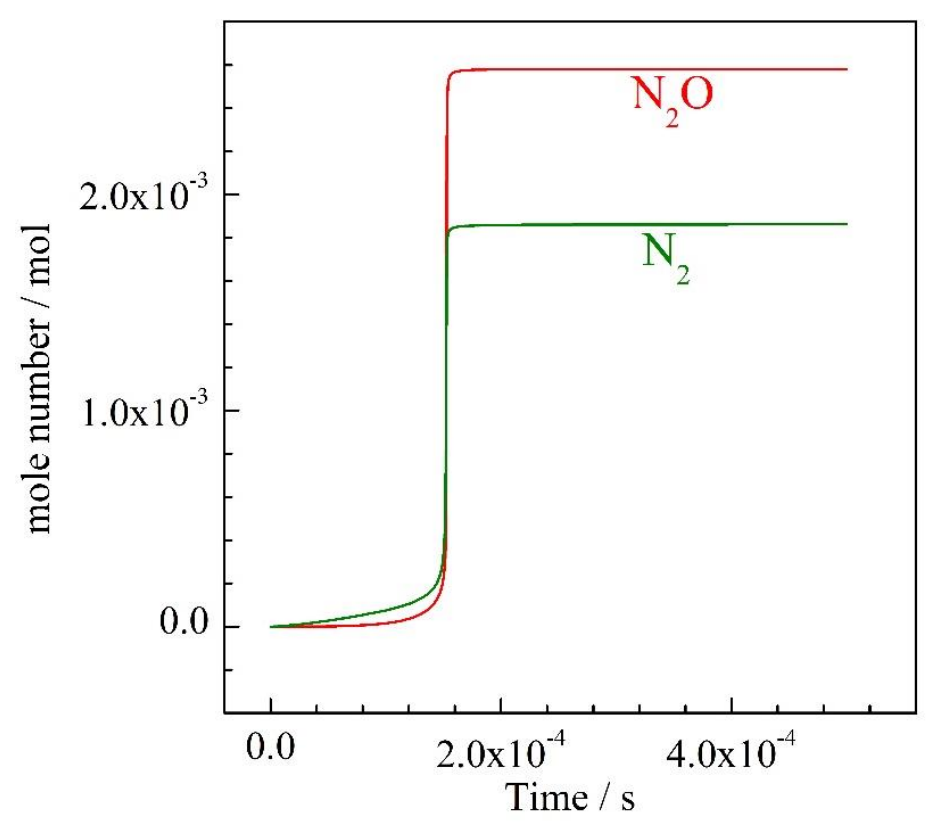

Figure 8 Temporal profiles of $\mathrm{N}_{2}$ and $\mathrm{N}_{2} \mathrm{O}$ from $\mathrm{AN}$ decomposition at initial temperature of $823 \mathrm{~K}$. This profile was simulated based on the YNU-L 1.0 model.

\section{Conclusions}

We analyzed the kinetics of the thermal decomposition of liquid AN based on results obtained from detailed reaction simulations. The model employed included both ionic and radical reaction mechanisms associated with AN. Rate coefficients were calculated to allow TS theory analyses of the reactions identified in a previous study. The rate coefficients for radical recombination reactions and proton transfers with no energy barriers were set to the diffusion limited value of $10^{-9} \mathrm{~cm}^{3} \mathrm{~mol}^{-1} \mathrm{~s}^{-1}$. Thermal correction, entropy and heat capacity values were then calculated from the partition function using statistical machinery. The heats of formation for gas-phase molecules were determined by the traditional atomization method combined 
with the G4 level of theory. The heats of formation of molecules in solution were obtained from the gas-phase heats of formation and the enthalpies of solvation at 298.15 K. An $a b$ initio model was used to simulate thermal behavior (i.e., heat flow) during AN decomposition. The simulated heat flow curves were elaborated by the Friedman method. The activation energy for the exothermic decomposition had a range of approximately $162-168 \mathrm{~kJ} \mathrm{~mol}^{-1}$ with $\alpha$ values between 0.1 and 0.5 . The activation energy reported for the liquid-phase thermal decomposition of $\mathrm{AN}$ is $170 \mathrm{~kJ} \mathrm{~mol}^{-1}$ [19], and this agreement supports validity of the YNU-L 1.0 model. Calculations of $\mathrm{TMR}_{\mathrm{ad}}$ based on the Friedman kinetic model provided accurate predictions below $623 \mathrm{~K}$. There was a difference of more than one order of magnitude between the $\mathrm{TMR}_{\mathrm{ad}}$ values obtained from the model-free Friedman model and YNU-L 1.0 model approaches at $823 \mathrm{~K}$. Analyses of variations in the evolved products indicated that the dominant mechanism transitions from ionic to radical decomposition with temperature increase. Thermal behavior predictions based on kinetic analysis using thermal analysis are evidently accurate when the dominant reaction in the thermal analysis is the same as the reaction under the experimental conditions. $\mathrm{TMR}_{\mathrm{ad}}$-based studies using the model-free kinetics were found to generate errors when the dominant reaction mechanism changes with temperature. These errors should be taken into consideration when $\mathrm{TMR}_{\mathrm{ad}}$ values are being calculated to evaluate the safe operational temperatures of chemicals based on kinetic data.

Detailed chemical reaction simulations revealed that the thermal explosion occurs after an induction period. The ionic reaction, $\mathrm{AN} \rightarrow \mathrm{N}_{2} \mathrm{O}+2 \mathrm{H}_{2} \mathrm{O}$, starts the decomposition reaction with exothermic heat during the induction period and the temperature increases gradually. As a result of increasing in temperature, the radical mechanism overwhelms the ionic mechanism. After radical initiation, a thermal explosion is ignited, and the temperature rises sharply.

Acknowledgement

This research was supported by JSPS KAKENHI Grant Number 17 H00844.

Reference

1. Oxley JC, Smith JL, Wang W. Compatibility of ammonium nitrate with monomolecular explosives. Part II nitroarenes. J Phys Chem. 1994;98:3901-7.

2. Marlair G, Kordek M. Safety and security issues relating to low capacity storage of AN-based fertilizers. J Hazard Mater. 2005;A123:13-28.

3. U.S. chemical safety and hazard investigation boad. Investigation report, final, West fertilizer company fire and explosion, REPORT 2013-02-I-TX.

4. Dechy N, Bourdeaux T, Ayrault A, Kordek M, Coze JL. First lessons of the Toulouse ammonium nitrate disaster, 21st September 2001, AZF plant, France. J Hazard Mater. 2004; $11: 131-8$.

5. Oommen C, Jain SR. Ammonium nitrate: a promising rocket propellant oxidizer. J Hazard Mater. 1999;A67:253-81.

6. Chaturvedi S, Dave PN. Review on thermal decomposition of ammonium nitrate. J Energ Mater. 2013;31:1-26.

7. Sinditskii VP, Egorshev VY, Levshenkov AI, Serushkin VV. Ammonium nitrate: combustion mechanism and the role of additives. Propellants Explos Pyrotech. 2005;30:269-80.

8. Manelis GB, Nazin GM, Rubtsov YI, Strunin VA. Thermal decomposition and combustion of explosives and propellants. CRC Press: Boca Raton; 2003.

9. Koroban VA, Burtsev YN, Alimov FR, Haustov AD, Dubovik VA, Teselkin VA, Thermal decomposition features of ammonium nitrate and its boron mixture under high pressures. Propellants Explos Pyrotech. 2004;19:307-10.

10. Cagnina S, Rotureau P, Singh S, Turcotte R, Fayet G, Adamo C. Theoretical and experimental study of the reaction between ammonium nitrate and sodium salts. Ind Eng Chem Res. 2016;55:12183-90.

11. Kajiyama K, Izato Y, Miyake A. Thermal characteristics of ammonium nitrate, carbon, and copper (II) oxide mixtures. J Therm Anal Calorim. 2013;113:1475-80.

12. Izato Y, Date S, Miyake A. Combustion characteristics of ammonium nitrate and carbon mixtures based on a thermal decomposition mechanism. Propellants Explos Pyrotech. 2013;38:129-35.

13. Brower KR, Oxley JC, Tewari MP. Evidence for hemolytic decomposition of ammonium nitrate at high temperature. J Phys Chem. 1989;93:4029-33.

14. Park J, Lin MC. Thermal decomposition of gaseous ammonium nitrate at low pressure: kinetic modeling of product formation and heterogeneous decomposition of nitric acid. J Phys Chem 


\section{A. 2009;113:13556-61}

15. Skarlis SA, Nicolle A, Berthout D, Duajardin C, Granger P, Combined experimental and kinetic modeling approaches of ammonium nitrate thermal decomposition. Thermochimica Acta. 2014;584:58-66.

16. Izato Y, Koshi M, Miyake A. Identification of thermal decomposition products and reactions for liquid ammonium nitrate on the basis of $\mathrm{ab}$ initio calculation. Int $\mathrm{J}$ Chem Kinet. 2016;49:83-99.

17. Chai JD, Gordon MH. Long-range corrected hybrid density functionals with damped atomatom dispersion corrections. Phys Chem Chem Phys. 2008;10:6615-20.

18. Montgomery JA, Frisch MJ, Ochterski JW, Petersson GA. A complete basis set model chemistry. VI. Use of density functional geometries and frequencies. J Chem Phys 1999;110:2822-7.

19. Willis A, Rosser S, Inami H, Wise H. The Kinetics of decomposition of liquid ammonium nitrate. J Phys Chem. 1963;67:1753-7.

20. Izato Y, Miyake A. A condensed phase decomposition mechanism for ammonium nitrate. Sci Technol Energe Materl. 2015;76:98-103

21. Vyazovkin S, Clawson JS, Wight CA. Thermal dissociation kinetics of solid and liquid ammonium nitrate. Chem Mater. 2001;13:960-6.

22. Izato Y, Miyake A. Identification of radical reactions and products for aqueous hydroxylamine nitrate (HAN) solution based on ab initio calculations. Sci Technol Energe Materl. 2018 in press

23. Miyoshi A. GPOP software, rev. 2013.07.15m7, available from the author. See http://akrmys.com/gpop/.

24. Nikolaidis A, Rauk A, Glukhovtsev MN, Radom L. Heats of formation from G2, G2(MP2), and G2(MP2,SVP) total energies. J Phys Chem. 1996;100:17460-564.

25. Curtiss LA, Redfern PC, Raghavachari K. Gaussian-4 theory. J. Chem. Phys. 2007;126:1-12.

26. Frisch MJ, Trucks GW, Schlegel HB, Scuseria GE, Robb MA, Cheeseman JR, Scalmani G, Barone V, Mennucci B, Petersson GA, Nakatsuji H, Caricato M, Li X, Hratchian HP, Izmaylov AF, Bloino J, Zheng G, Sonnenberg JL, Hada M, Ehara M, Toyota K, Fukuda R, Hasegawa J, Ishida M, Nakajima T, Honda Y, Kitao O, Nakai H, Vreven T, Montgomery JA, Peralta JE, Ogliaro F, Bearpark M, Heyd JJ, Brothers E, Kudin KN, Staroverov VN, Keith T, Kobayashi R, Normand J, Raghavachari K, Rendell A, Burant JC, Iyengar SS, Tomasi J, Cossi M, Rega N, Millam JM, Klene M, Knox JE, Cross JB, Bakken V, Adamo C, Jaramillo J, Gomperts R, Stratmann RE, Yazyev O, Austin AJ, Cammi R, Pomelli C, Ochterski JW, Martin RL, Morokuma K, Zakrzewski VG, Voth GA, Salvador P, Dannenberg JJ, Dapprich S, Daniels AD, Farkas O, Foresman JB, Ortiz JV, Cioslowski J, Fox DJ. Gaussian 09, Revision C.01. Gaussian, Inc., Wallingford CT; 2010

27. Yamashita A, Asai K. Dielectric anomaly of ammonium nitrate in low frequency region. J Phys Soc Japan. 1963;18:1247-53.

28. CHEMKIN-PRO 15131, Reaction Design: San Diego, 2013.

29. Friedman HL. Kinetics of thermal degradation of char-forming plastics from thermogravimetry. Application to a phenolic plastic, J Polym Sci C. 1963;6:183-95.

30. Ozawa T. Applicability of friedman plot. Journal of Thermal Analysis. 1986;31:547-51.

31. Izato Y, Miyake A. Thermal decomposition of molten ammonium nitrate (AN). J Therm Anal Calorim (2015) 122;595-600 